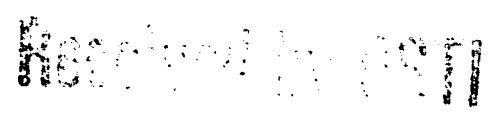

\title{
Effects of Oxide Layers on Optical Properties and X-Ray Hardness of Al-Be Mirrors
}

\author{
Richard H. White \\ G. Richard Wirtenson
}

June 11, 1991

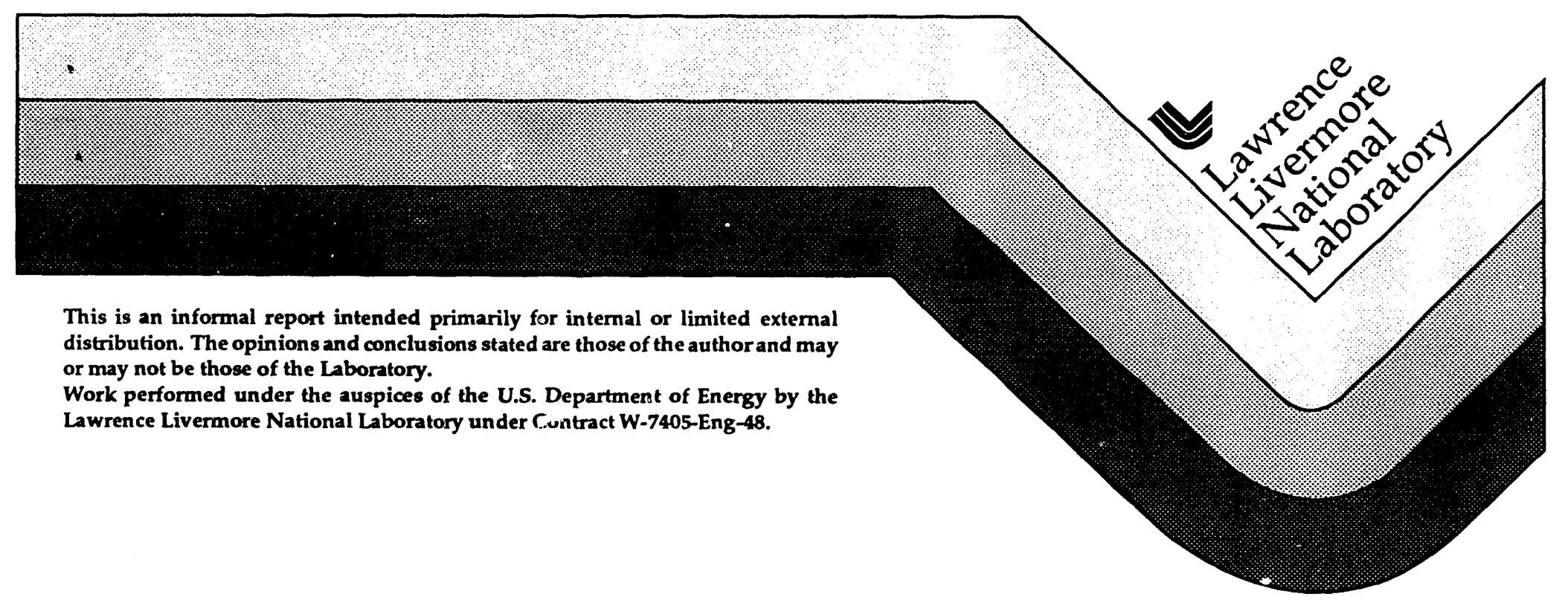




\section{DISCLAIMER}

This document was prepared as an acccount of work spensored by an agency of the United States Government. Neither the United States Government nor the University of California nor any of their employees, makes any warranty, express or implied, or assumes any legal liability or responsibility for the accuracy, completeness, or usefulness of anyinformation, apparatus, product, or process disclosed, or represents that its use would not infringe privately own rights. Reference herein to any specific commercial products, process, or service by trade name, trademark, manufacturer, or otherwise, does not necessarily constitute or imply its endorsement, recommendation, or favoring by the United States Government or the University of California. The views and opinions of authors expressed herein do not necessarily state or reflect those of the United States Government or the University of California, and shall not be used for advertising or product endorsement purposes.

This report has been reproduced directly from the best available copy.

Available to DOE and DOE contractors from the Office of Scientific and Technical Information P.O. Box 62, Oak Ridge, TN 37831

Prices available from (615) 576-8401, FTS 626-8401

Available to the public from the National Technical Information Service

U.S. Department of Commerce 5285 Port Royal Rd., Springfield, VA 22161 


\title{
Effects of Oxide Layers on Optical Properties and X-ray Hardness of Al-Be Mirrors
}

Richard H. White and G. Richard Wirtenson

\author{
University of California \\ Lawrence Livermore National Laboratory \\ P.O. Box 808, L-298 \\ Livermore, CA 94550
}

\begin{abstract}
Oxide layers form on the surfaces of many metallic mirrors. The oxidation may occur during fabrication or after the mirror is finished and installed. Some oxide layers may be intentionally added to protect the mirror or to change its optical properties. Computer calculations predict the effect of oxide layers on optical and ultraviolet reflectance as well as the $x$-ray absorption and concomitant thermal damage to the mirrors.
\end{abstract}

\section{INTRODUCTION}

A thin aluminum reflective coating applied to a beryllium substrate produces a mirror that has high reflectivity over a wide spectral range and yet resists damage by soft x-ray's, even at fluences exceeding $1 \mathrm{cal} / \mathrm{cm}^{2}$ and for pulse durations as short as $5 \mathrm{~ns}$. After manufacture of such mirrors, it is inevitable that at least some thin oxide layers form on the various mirror surfaces. These may grow thicker with the passage of time.

The computer code LXRT is used to explore the effect of oxide layers on the melt fluence of aluminum - beryllium mirrors exposed to soft $x$ rays. (See Section II for a description of LXRT.) The thermal response of mirrors to deposited $x$ rays strongly depends upon the incident $x$-ray spectrum and the $x$-ray pulse length. Unless otherwise noted, all calculations reported here are for a $1 \mathrm{keV}$ blackbody 
spectrum and a temporal pulse shaped as an isosceles triangle, $10 \mathrm{~ns}$ across the base. (The intensity rises linearly with time to a maximum in $5 \mathrm{~ns}$, then falls linearly to zero in ar.other $5 \mathrm{~ns}$.)

The mirror design considered here is an aluminum reflective coating, 10 to $100 \mathrm{~nm}$ thick, on a beryllium substrate. The dependence of reflectarice and melt fluence upon thickness of the aluminum reflector is explored for "bare" aluminum on beryllium mirrors. Oxidc layers in various combinations are added to this configuration (Fig. 1). Reflectances and melt fluences are calculated for these "oxidized" mirrors.

Oxide layers may be intentionally deposited to act as heat sinks, to protect the surface from mechanical or chemical damage, or to alter the optical properties of the mirror. Intentionally deposited oxide layers of various thicknesses are explored. Layers intentionally deposited on the front (irradiated) surface of the mirror are herein called "coatings" or "coats."

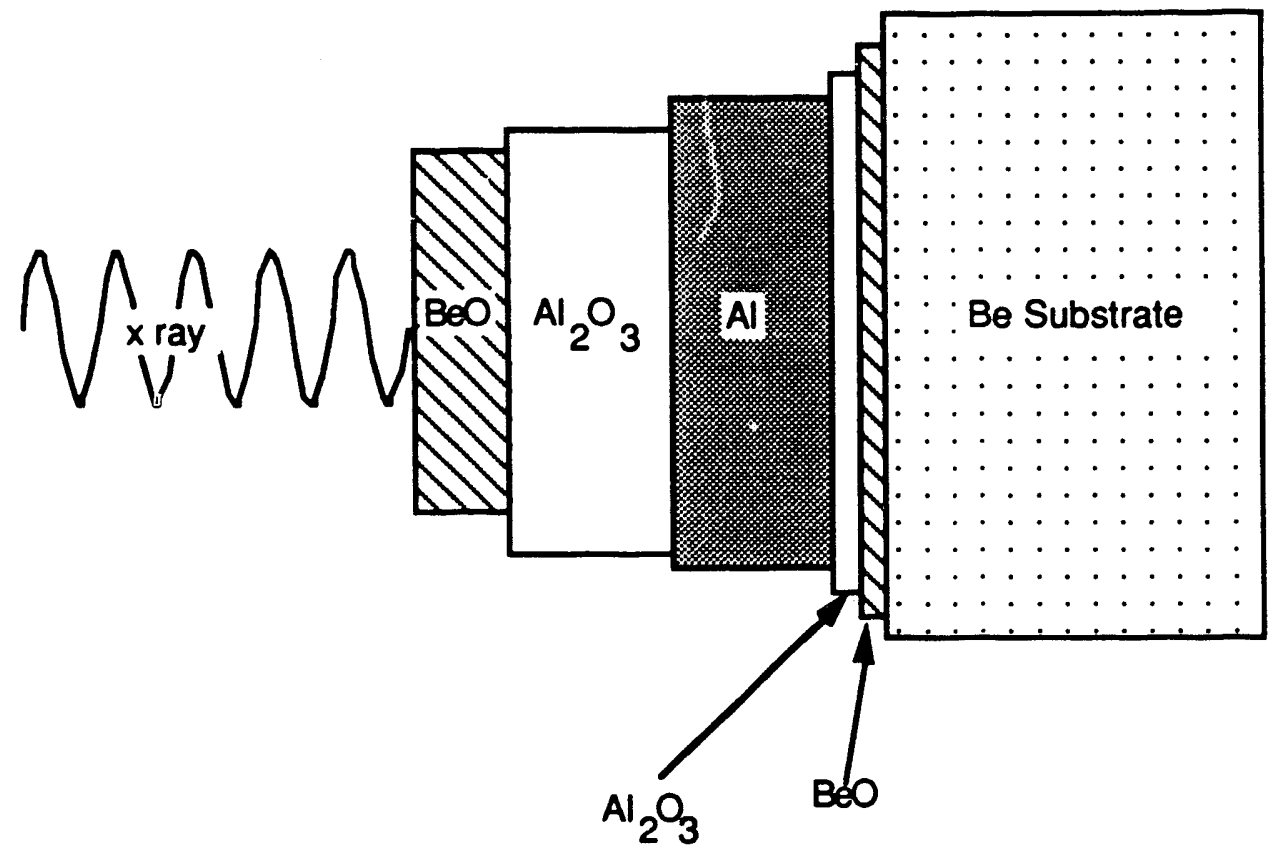

Fig. 1 Aluminum-beryllium mirror with various possible oxide layers shown. Some oxide layers may have zero thickness. 


\section{MODELING USING LXRT}

LXRT is a version of the XRTH computer code developed by J.R. Triplett et al. of S-Cubed corporation. ${ }^{1}$ It is a one-dimensional calculation. Incident radiation is described by a frequency independent temporal pulse shape and a frequency dependent intensity. $X$ ray deposition is zy exponential attenuation. Secondary $x$ rays, produced by scattering and fluorescence, are analyzed by a discrete ordinates method. Electron transport is calculated using a P1 approximation to the Spencer-Lewis equation. A time-dependent energy deposition and heat diffusion calculation follows this determination of energy deposition by $x$ rays and electrons. Melting and vaporization are treated. A succinct summary of the physics embraced by LXRT (and XRTH), including differential equations and boundary conditions is given in the article by Rhoades and Triplett ${ }^{2}$.

The reported calculations do not assess damage due to thermally induced stress. Calculated melt fluences are given. Damage often occurs at a fluence somewhat less than the calculated melt fluence. Nevertheless, the patterns of heat flow are essentially the same whether a mirror is subjected to melt fluence or to a fluence somewhat below melt fluence. The calculated melt fluence is a useful indicator of vulnerability and defines an ideal upper limit on performance.

Though LXRT includes an optional one-dimensional hydrodynamic calculation that couples to the thermal transport, this option was disabled in all reported calculations. Experience shows that a one-dimensional treatment of hydrodynamics cannot credibly calculate the stresses developed at interfaces between thin layers of materials, which expand transversely at markedly different rates.

In all calculations reported here, material properties are taken from the compilation prepared by $\mathrm{Childs}^{3}$. (Note that this compilation is for bulk materials and does not necessarily correspond to the data applicable to thin films. In particular, thin films that exhibit structural disorders introduced during their construction may have thermal conductivities an order of magnitude less than those of the bulk material. ${ }^{4}$ ) 


\section{ALUMINUM MIRRORS}

The reflectance of bare polished beryllium is about $50 \%$ for incident wavelengths ranging from visible light through the near ultra-violet. The reflectance of polished aluminum, in this same spectral region, is over $90 \%$. Aluminum films can be deposited onto beryllium mirrors to enhance reflectance.

Figure 2 shows how reflectance (at $250 \mathrm{~nm}$ wavelength) depends upon aluminum film thickness for an aluminum-beryllium mirror. ${ }^{5}$ In general, the reflectance increases as the aluminum film thickness increases and asymptotically approaches an upper limit that is the reflectance of a thick aluminum slab.

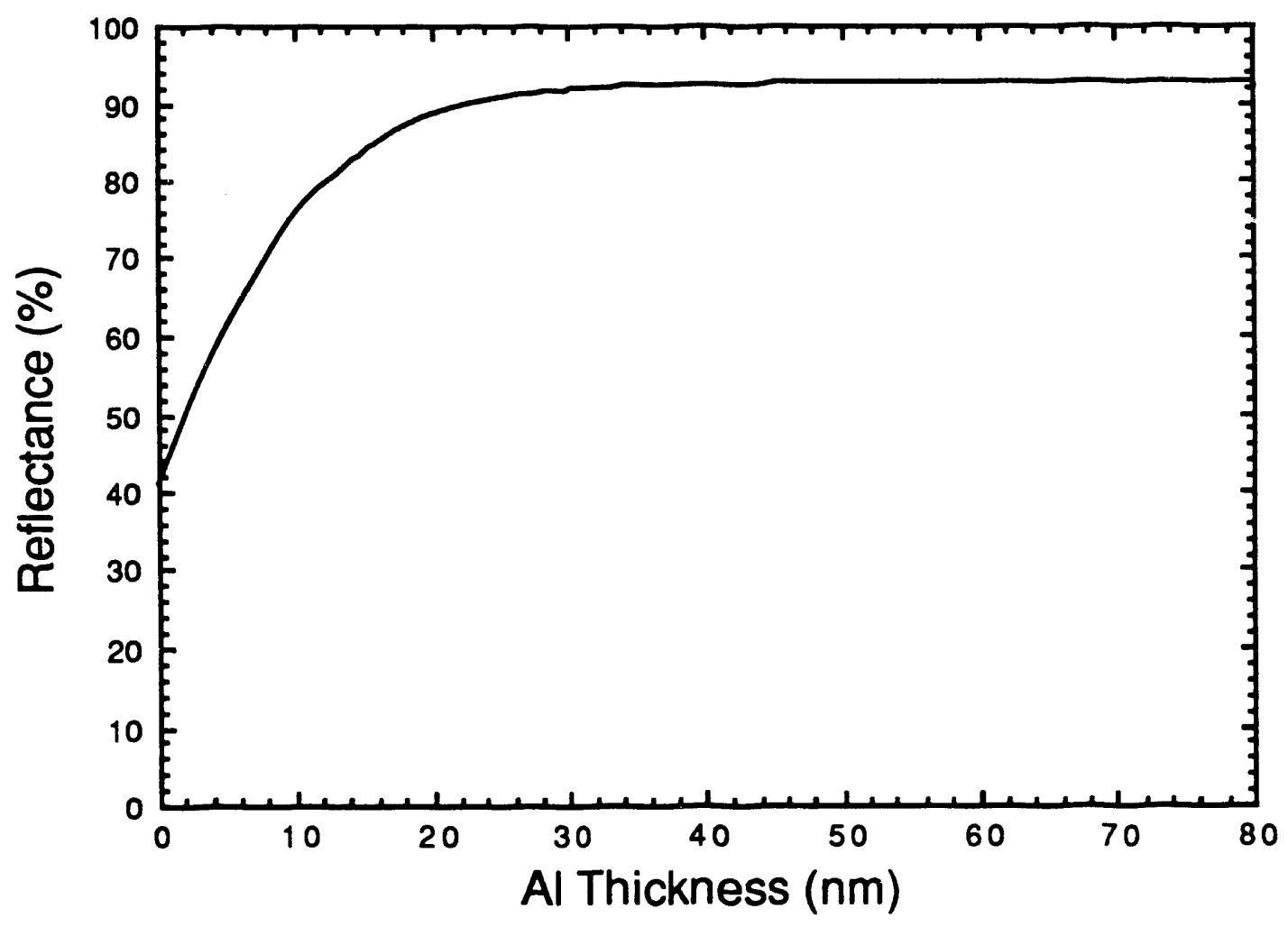

Fig. 2 Reflectance of $250 \mathrm{~nm}$ wavelength vs. reflector thickness for a mirror with an aluminum reflector on a beryllium substrate.

According to Fig. 2, fifty nanometers of aluminum brings the reflectance of a $250 \mathrm{~nm}$ wavelength very near its limiting value. Fifty nanometers of aluminum give nearly the limiting reflectance for wavelengths longer than $250 \mathrm{~nm}$, as well. 
The need to make films thick to provide maximum reflectance competes with a need to make them thin to decrease $x$-ray vulnerability. Figure 3 shows the dependence of melt fluence on reflector thickness for aluminum films on beryllium substrates with no oxide coats present. The incident spectrum is a $1 \mathrm{keV}$ blackbody. The temporal pulse shape is an isosceles triangle. The figure shows results of calculations for pulse durations (triangle base lengths) of 5,10 , and $20 \mathrm{~ns}$.

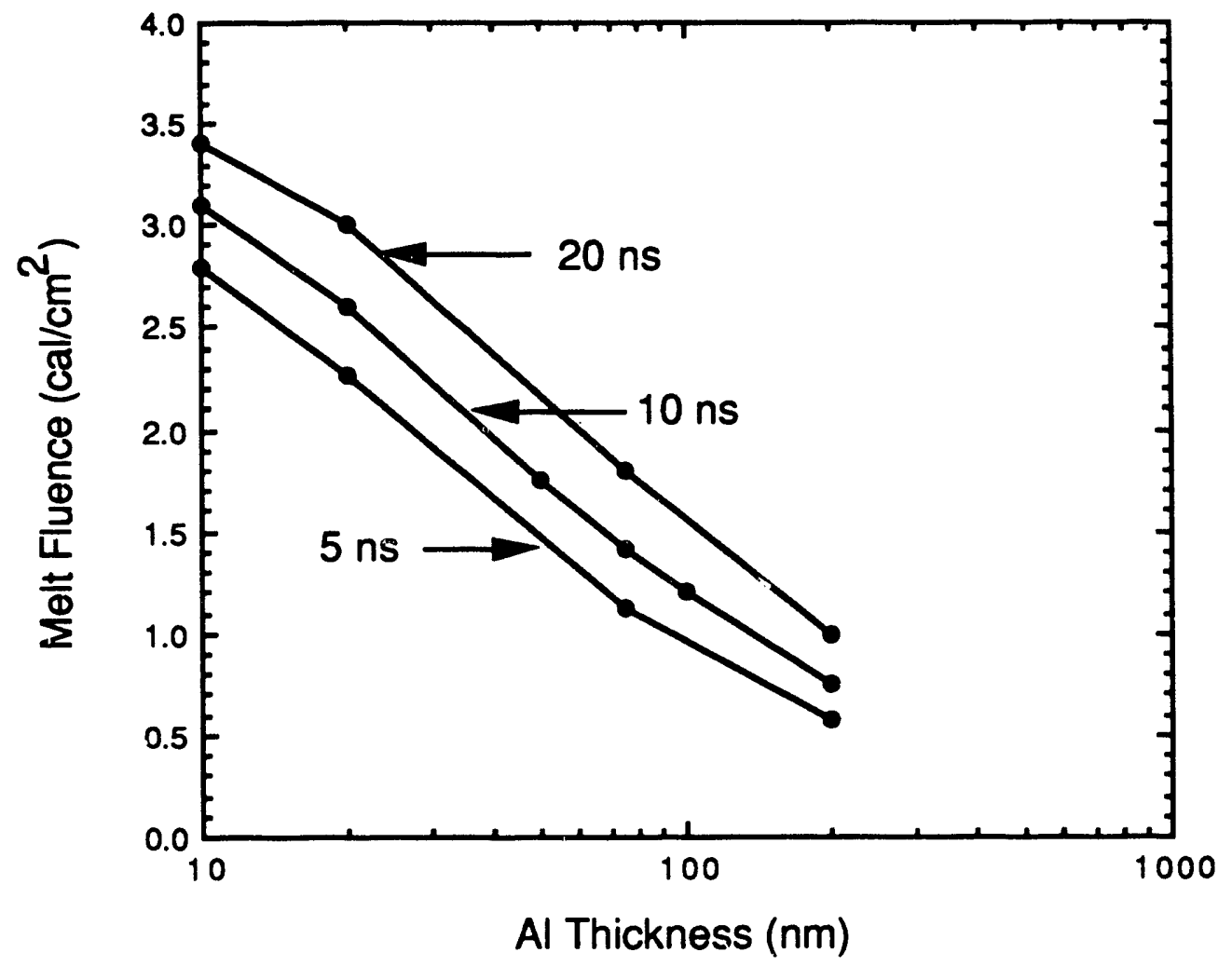

Fig. 3 Melt fluence vs. thickness of aluminium reflector for an aluminum-beryllium mirror with no oxide layers. The incident spectrum is a $1 \mathrm{keV}$ blackbody. The x-ray pulse is an isosceles triangle, with base 5,10 , or $20 \mathrm{~ns}$ (as indicated).

Blackbody spectra with temperatures higher that $1 \mathrm{keV}$ are less stressing on the system than the $1 \mathrm{keV}$ spectrum. For example, a $2 \mathrm{keV}$ blackbody spectrum delivered in a $10 \mathrm{~ns}$ triangular pulse melts $50 \mathrm{~nm}$ of aluminum on a beryllium substrate with the fluence $7.4 \mathrm{cal} / \mathrm{cm}^{2}$. For a $1 \mathrm{keV}$ spectrum in a $10 \mathrm{~ns}$ triangular pulse, this same mirror design melts at $1.8 \mathrm{cal} / \mathrm{cm}^{2}$. 


\section{ALUMINUM OXIDE ON THE FRONT SURFACE}

Aluminum Oxide $\left(\mathrm{Al}_{2} \mathrm{O}_{3}\right)$ coats may be applied to the front surface of the mirror either to alter the optical properties or as a protective coating for the aluminum reflector. Figure 4 compares the reflectances, as a function of wavelength, for aluminum mirrors with and without oxide coats. Each mirror consists of $50 \mathrm{~nm}$ of aluminum on a beryllium substrate. The oxide coated mirror has a $20 \mathrm{~nm}$ thick coat of aluminum oxide.

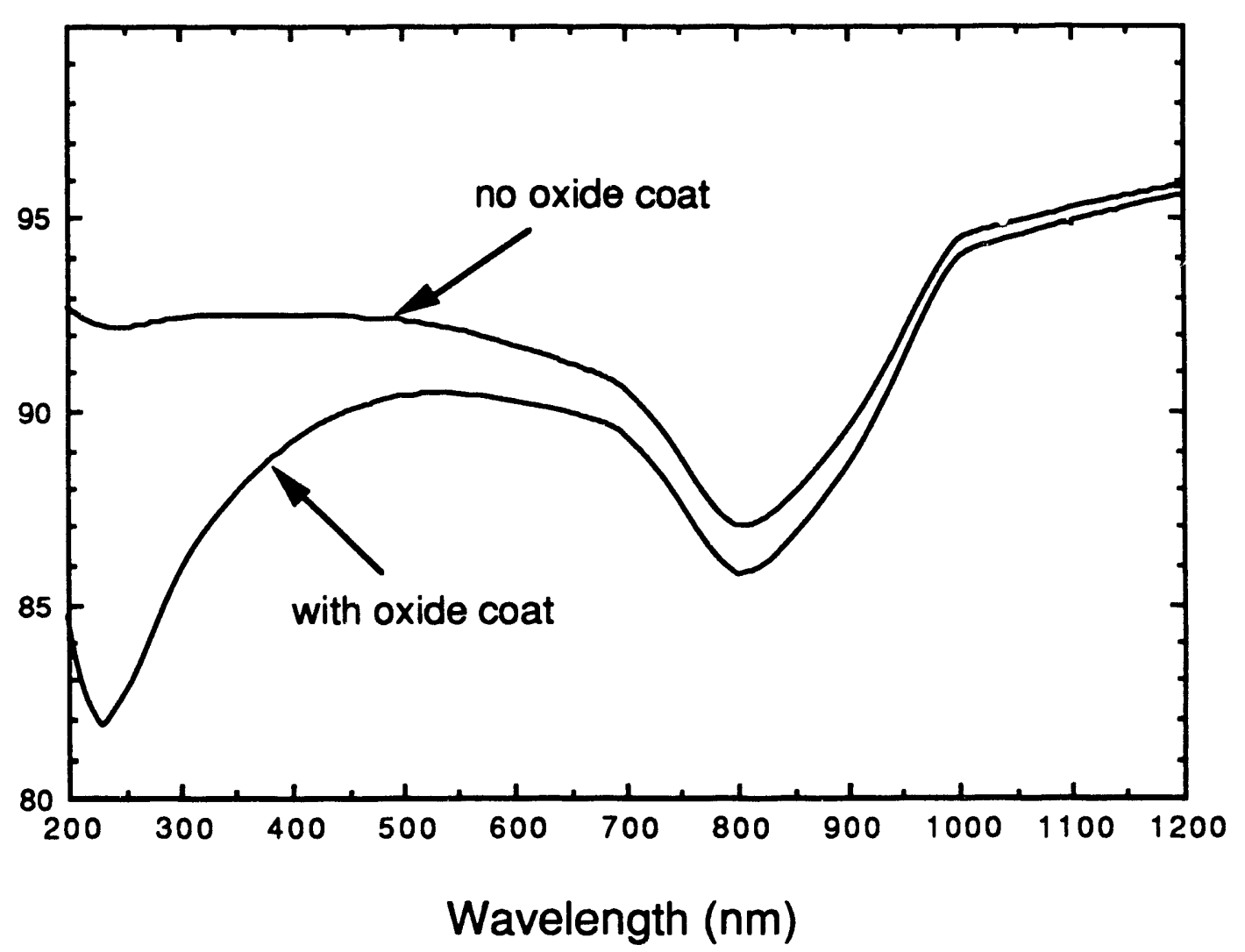

Fig. 4 Reflectance vs. reflected wavelength for mirrors with and without oxide coats. The $\mathrm{Al}$ reflector thicknesses are each $50 \mathrm{~nm}$. Substrates are Be. The oxide coated mirror has a $20 \mathrm{~nm}$ coat of $\mathrm{Al}_{2} \mathrm{O}_{3}$.

The solid curve in Fig. 5 gives the dependence of melt fluence on oxide coat thickness for a mirror consisting of an aluminum oxide coat on a $20 \mathrm{~nm}$ aluminum reflecting film on a beryllium substrate. The mirror may be destroyed either because the aluminum reflector melts or because the oxide coat melts. For some coat thicknesses, the aluminum melts at a lower fluence than does the oxide coat; for other coat thicknesses, the coat melts at a lower fluence than the 
reflector. The melt fluences for the aluminum reflector and aluminum oxide coat are shown with dashed lines in Fig. 5 . The specirum is a $1 \mathrm{keV}$ blackbody and the pulse is a triangle with a $10 \mathrm{~ns}$ base.

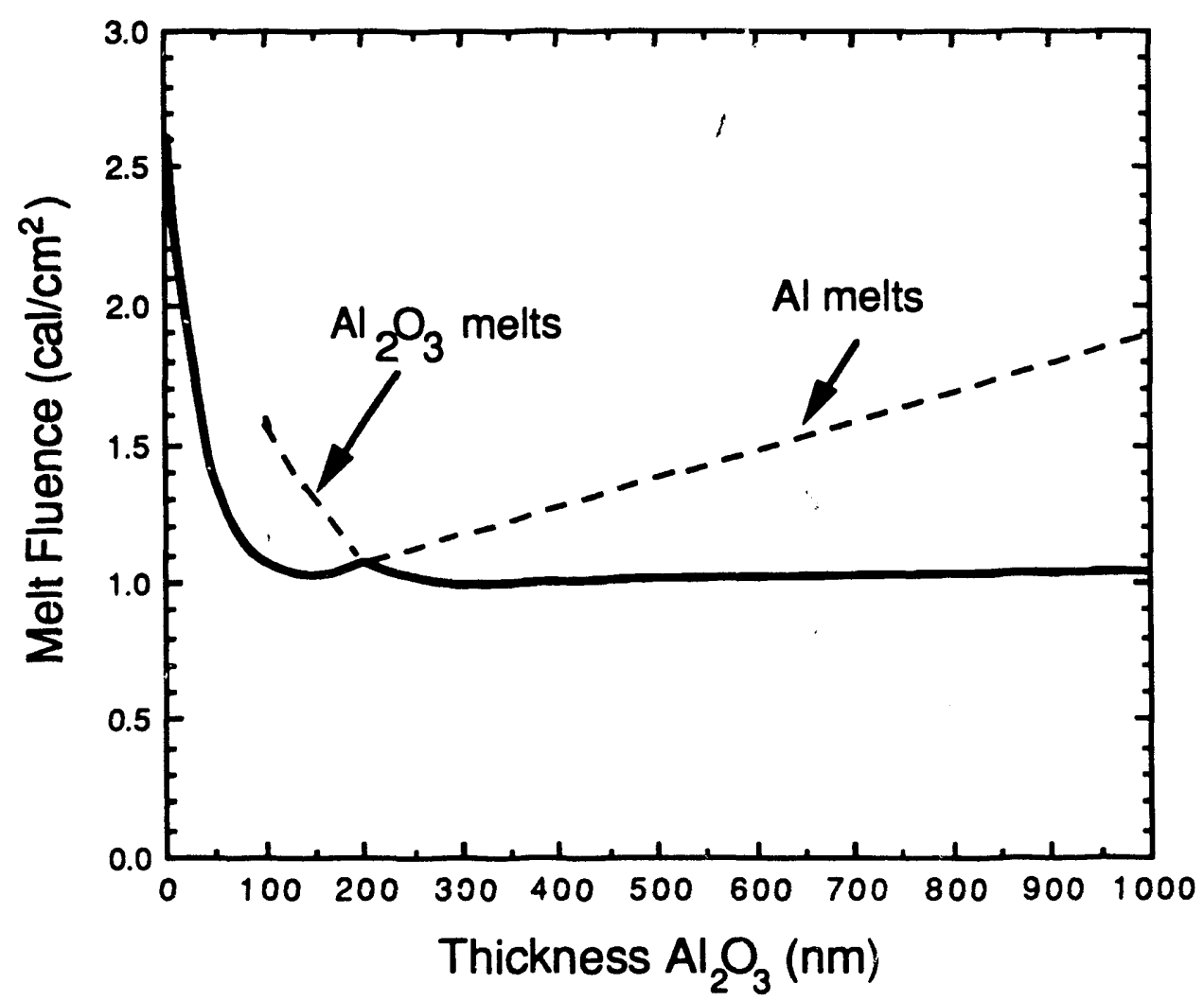

Fig. 5: Melt fluence vs. oxide coat thickness for an $\mathrm{Al}_{2} \mathrm{O}_{3}$ coat on $20 \mathrm{~nm}$ of $\mathrm{Al}$ on a $\mathrm{Be}$ substrate. The spectrum is a $1 \mathrm{keV}$ blackbody. The pulse is a $10 \mathrm{~ns}$ isosceles triangle. One dashed curve gives the fluence that melts the $\mathrm{Al}$ reflector, the other dashed curve is the melt fluence for the $\mathrm{Al}_{2} \mathrm{O}_{3}$ coat. The melt fluence for the coated mirror is the lesser of these as indicated by the solid line.

The mirror melt fluence versus oxide thickness indicated by the curves in Fig. 4 shows four distinct features.

1) For oxide coats between 0 and $1 \mathrm{~nm}$ thick, the melt fluence is essentially the same as for a bare aluminum reflector: $2.6 \mathrm{cal} / \mathrm{cm}^{2}$.

2) For oxide coats thicker than about $1 \mathrm{~nm}$, the melt fluence drops sharply from the value for bare aluminum. The decline in melt fluence with increasing oxide-coating thickness continues to a minimum of 1.05 $\mathrm{cal} / \mathrm{cm}^{2}$ for an oxide coat $100 \mathrm{~nm}$ thick. 
3) As the oxide coat thickness increases beyond $100 \mathrm{~nm}$, the melt fluence of the aluminum increases. This is because the thick coat acts as a combined $x$-ray shield and heat sink. The part of the oxide coat near the irradiated surface absorbs the $x$ rays so they do not reach the aluminum reflector. The coat is thick enough that when the resultant heat is distributed through the coat, the temperature remains too low to melt the adjacent aluminum.

4) As the oxide coat thickness increases beyond $200 \mathrm{~nm}$, the oxide itself melts at a fluence of about $1 \mathrm{cal} / \mathrm{cm}^{2}$. In general, it then takes a somewhat higher fluence to melt the aluminum but the optical figure of the mirror has already been destroyed due to the melting of the oxide.

Figure 6 compares the melt fluence versus oxide thickness curves for reflectors of 20,50 , and $100 \mathrm{~nm}$. The behaviors of the 50 and $100 \mathrm{~nm}$ reflectors are similar to that described for the $20 \mathrm{~nm}$ reflector.

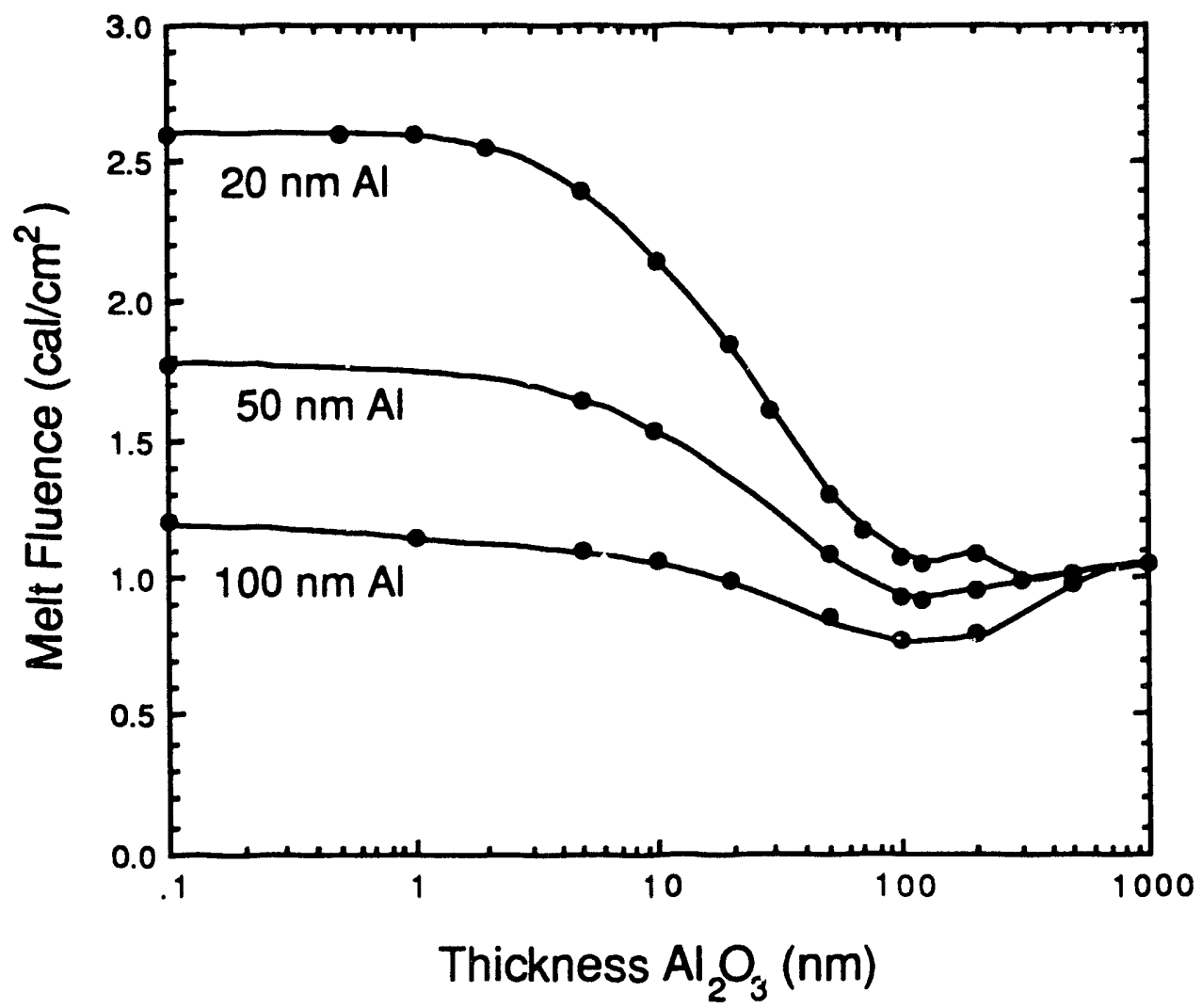

Fig. 5: Melt fluence vs. oxide coat thickness for an $\mathrm{Al}_{2} \mathrm{C}_{3}$ coat on an $\mathrm{Al}$ reflector on a Be substrate. Curves are shown for 20,50 and $100 \mathrm{~nm}$ reflectors. The spectrum is a 1 $\mathrm{keV}$ blackbody. The pulse is a $10 \mathrm{~ns}$ isosceles triangle. 


\section{BERYLLIUM OXIDE ON THE FRONT SURFACE}

Though aluminum oxide forms a naturally occurring coating on aluminum reflectors, aluminium oxide coats thicker than about $1 \mathrm{~nm}$ sericusly degrade a mirror's hardness to $x$ rays. Beryllium oxide has lower $x$-ray absorption and larger heat capacity per unit volume than does aluminum oxide. This suggests that it may be a useful coating material. ${ }^{6}$

Melt fluences were calculated for a mirror with a beryllium oxide coat on the front surface. (The optical performance of beryllium oxide is similar to aluminum oxide; therefore, no additional reflectance calculations were done.) Figure 6 shows the melt fluence versus thickness for a $50 \mathrm{~nm}$ aluminum reflector coated with various thicknesses of either aluminum oxide or beryllium oxide. The incider $c$ spectrum is a $1 \mathrm{keV}$ blackbody. The $\mathrm{x}$-ray pulse is a $10 \mathrm{~ns}$ isosceles triangle.

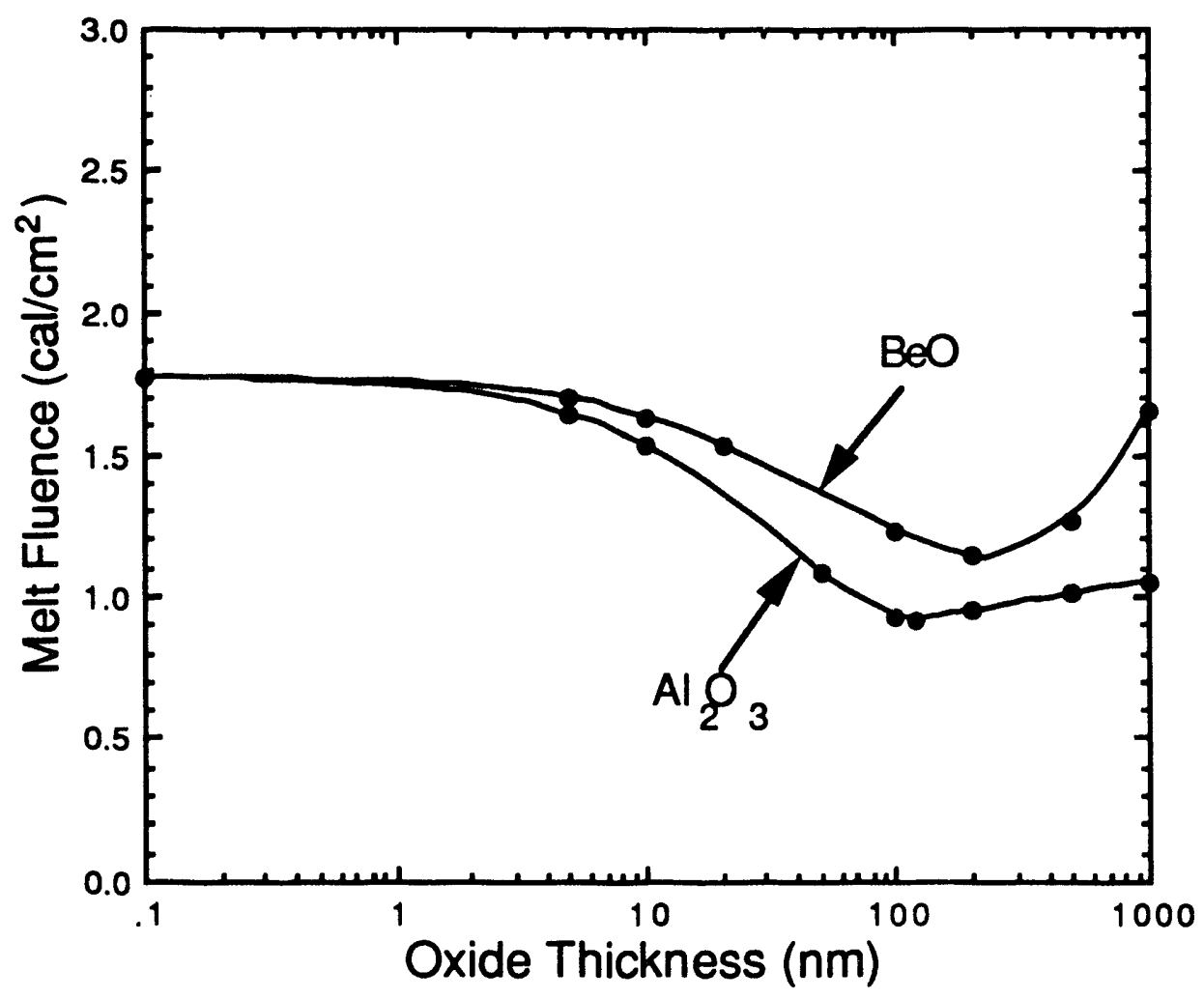

Fig. 6 Melt fluence vs. oxide coat thickness for mirrors with an oxide coat ( $\mathrm{BeO}$ or $\mathrm{Al}_{2} \mathrm{O}_{3}$ ) on $50 \mathrm{~nm}$ of $\mathrm{Al}$ on a Be substrate. The spectrum is a $1 \mathrm{keV}$ blackbody. The pulse is a $10 \mathrm{~ns}$ isosceles triangle. 
Beryllium oxide coated mirrors are less susceptible to $x$-ray thermal effects than mirrors coated with aluminum oxide. This is because beryllium oxide absorbs less x-ray energy and has a higher specific heat than aluminum oxide. Increasing the beryllium oxide coat thickness degrades the hardness of the mirror until a coat thickness of about $200 \mathrm{~nm}$ is reached. Beryllium oxide coats thicker than $200 \mathrm{~nm}$ provide a heat sink for the energy deposited near the surface of the coat and hence increase the hardness. Even with beryllium oxide coats 1000 nm thick, a larger fluence is required to melt the oxide than to melt the aluminum reflector. This contrasts with the situation for aluminum oxide coats discussed in Section III.

\section{NATURALLY OCCURRING OXIDE LAYERS}

Sections IV and V treat oxide coats on the front surface. This section explores the effect of oxides on other surfaces. Here, the oxide layers are viewed as a byproduct of the manufacturing process. It is assumed that there has been no effort to increase the natural oxidation. Therefore, these naturally occurring oxide layers are assumed to be thin: $\sim 4 \mathrm{~nm}$ thickness.

The aluminum surface that adjoins the beryllium substrate has minimal exposure to oxygen during or after manufacture of the mirror. It is unlikely to be oxidized to the same degree as is the front surface. Nevertheless, for completeness, some calculations include a $4 \mathrm{~nm}$ deep oxidation of this "backside" of the aluminum. Calculations for $50 \mathrm{~nm}$ aluminum oxide and beryllium oxide coats on the front surface are reported. These are given for mirrors with and without expected naturally occurring oxide layers.

Table I summarizes the calculations that are for a $1 \mathrm{keV}$ blackbody spectrum delivered in an isosceles triangular pulse of duration $10 \mathrm{~ns}$. Calculated melt fluences are quoted to three figures only to display the relative effects of various oxide configurations. Accuracy is probably no better than ten percent and may be worse due to uncertainty in the physical properties of the thin films. 
TABLE I. Melt Fluences for Various Oxide Layer Configurations

(See Fig. 1 for schematic diagram of layer configurations)

\begin{tabular}{|c|c|c|c|c|c|}
\hline \multicolumn{5}{|c|}{ Layer Thickness (nm) } & \multirow{2}{*}{$\begin{array}{c}\text { Melt Fluence } \\
{\mathrm{cal} / \mathrm{cm}^{2}}^{2}\end{array}$} \\
\hline $\mathrm{BeO}$ & $\mathrm{Al}_{2} \mathrm{O}_{3}$ & Al & $\mathrm{Al}_{2} \mathrm{O}_{3}$ & $\mathrm{BeO}$ & \\
\hline 0 & 0 & 50 & 0 & 0 & 1.77 \\
\hline 0 & 0 & 50 & $\mathbf{0}$ & 4 & 1.76 \\
\hline 0 & 0 & 50 & 4 & 0 & 1.64 \\
\hline 0 & 0 & 50 & 4 & 4 & 1.60 \\
\hline 0 & 4 & 50 & 0 & 0 & 1.67 \\
\hline 0 & 4 & 50 & 0 & 4 & 1.63 \\
\hline 0 & 4 & 50 & 4 & 0 & 1.53 \\
\hline 0 & 4 & 50 & 4 & 4 & 1.49 \\
\hline 0 & 50 & 50 & 0 & 0 & 1.08 \\
\hline 0 & 50 & 50 & 0 & 4 & 1.07 \\
\hline 50 & 0 & 50 & 0 & 0 & 1.38 \\
\hline 50 & 4 & 50 & c & 4 & 1.31 \\
\hline
\end{tabular}

\section{CONCLUSIONS}

Aluminum films of thickness of order $50 \mathrm{~nm}$ or more, deposited on a beryllium substrate, have substantially higher reflectivity than a bare beryllium mirror.

Ultra thin (< $1 \mathrm{~nm}$ ) oxide coats do not alter the damage threshold of aluminum-beryllium mirrors. Coats of thickness between 1 and $10 \mathrm{~nm}$ moderately increase vulnerability to $x$ rays. Oxide coats of thickness 10 to $100 \mathrm{~nm}$ significantly increase $x$-ray vulnerability. Beryllium oxide coats do not increase vulnerability as much as do aluminum oxide coats.

Coats of beryllium oxide exceeding $100 \mathrm{~nm}$ in thickness act as heat sinks for the energy absorbed near the irradiated surface and provide some protection against $x$-ray induced thermal damage. However, even a $1000 \mathrm{~nm}$ thick beryllium oxide coating will not match the performance of a"bare" aluminum-beryllium mirror. 
Naturally occurring oxide layers of about $4 \mathrm{~nm}$ thickness slightly increase a mirror's vulnerability to $x$ rays. With probable naturally occurring oxidation configurations, the net effect is approximately a $10 \%$ decrease in melt fluence.

This work was performed under the auspices of the U.S. Department of Energy by the University of California, Lawrence Livermore National Laboratory under Contract W-7405-Eng-48.

\section{REFERENCES}

1J.R. Triplett, B. Shkoller, and M. Merker, "XRTH User's Manual and Reference Guide", SCubed, La Jolla, CA, Report No. SSS-R-878420 (1986)

${ }^{2}$ C.E. Rhoades Jr. and J.R. Triplett, J Appl. Phys 69, 1909 (1991)

3 Childs, W.H. "Thermophysical Properties of Selected Space Related Materials" Aerospace Corp. , El Segundo, CA, Report TOR-0081(6435-02) [ 1981 (Vol I), 1986 (Vol II)].

4J.C. Lambropoulos, M.R. Jolly, C.A. Amsden, S.E. Gilman, M.J. Sinicropi, D. Diakomhalis, and S.D. Jacobs, J. Appl Phys. 68, 4230 (1989)

${ }^{5}$ All reflectance calculations reported here used the program "Film Calc" available from FTG Software Associates, P.O. Box 579, Princeton NJ, 08542

${ }^{6}$ G.R. Wirtenson, Patent Disclosure, LL.NL File No.IL-8136 with Department of Energy case No. S-68, 749 (RL-10,572) 

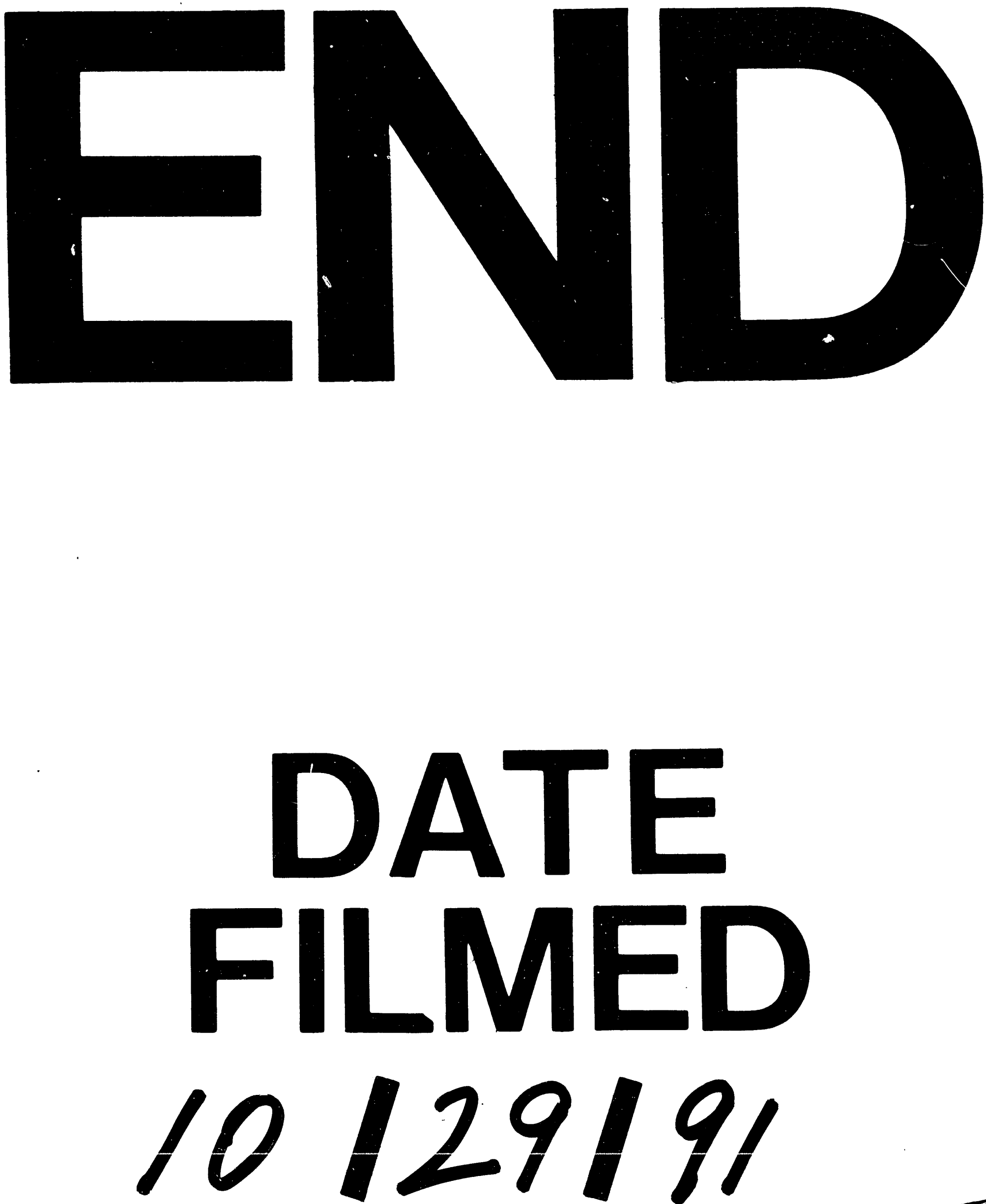
